\title{
Education, Lifelong Learning and Self-Rated Health in Later Life in the USA
}

\author{
Takashi Yamashita ${ }^{a}$, Anthony R. Bardo ${ }^{b}$, Darren Liu ${ }^{\mathrm{c}}$ and Ji Won Yoo ${ }^{\mathrm{d}}$ \\ a Department of Sociology, Anthropology, and Health Administration and Policy, University of \\ Maryland, Baltimore County, Baltimore, Maryland, USA \\ ${ }^{b}$ Department of Sociology, University of Kentucky, Lexington, Kentucky, USA \\ c Department of Public Health, Des Moines University, Des Moines, lowa, USA \\ ${ }^{\mathrm{d}}$ School of Medicine, University of Nevada, Las Vegas, USA
}

\begin{abstract}
Objective: This study examined the mediating effects of lifelong learning on the association between self-rated health and educational attainment among a nationally representative sample of the US residents aged 50 -years and older.

Setting: Socioeconomic disparities in health are a major public health concern in economically developed nations where improving socioeconomic status (e.g., formal educational attainment) at the population-level is challenging. In the light of population ageing, alternative approaches to improve health through malleable factors are urgently needed. Recent research suggests that participation in organised learning activities-lifelong learning-could attenuate the lack of formal educational attainment on health.

Methods: Data come from the 2012 wave of the US Health and Retirement Study. Structural equation models with bootstrapping were used to estimate the mediation effect of lifelong learning activity in the relationship between self-rated health and formal educational attainment.

Results: Approximately $3 \%$ to $5 \%$ of the effect of formal education on self-rated health was mediated by lifelong learning activity. Findings from this study support the notion that ongoing participation in organised learning activities is beneficial for health in later life. Conclusion: Lifelong learning reflects a promising autonomous and sustainable strategy to improve health in later life. Future public health and education policy as well as education institutions should consider providing more learning opportunities for older populations.
\end{abstract}

Key words: social determinants of health; life course; health disparities; socioeconomic status; older adults; USA

\section{Corresponding author:}

Takashi Yamashita, Department of Sociology, Anthropology, and Health Administration and Policy, University of Maryland, Baltimore County, 1000 Hilltop Circle, Baltimore, Maryland, 21250, USA Email: yamataka@umbc.edu 


\section{Introduction}

Educational attainment-often denoted by one's highest degree or total years of formal education-is well-recognised as a key fundamental determinant of health (Phelan et al., 2010). A person's educational attainment is typically determined by the time she or he reaches early adulthood. Yet, its effects on health are pervasive and cumulative, as related dis/advantages amplify in magnitude across the life course (Dupre, 2007). Education, as a marker of socioeconomic status, is linked to a collection of health resources such as health information, healthful behaviours (e.g., smoking), psychosocial resources (e.g., social network, self-efficacy), and health care utilisation (Hayward et al., 2015; Cutler and LlerasMuney, 2010). Increasing levels of education may be the best long-term public health strategy for achieving national health goals (Mirowsky and Ross, 2015). Yet, in terms of immediate improvements in population health, this approach is ineffective (Olshansky et al., 2012).

Increasing levels of education will likely result in improved population health, but improving one's socioeconomic status requires time and resources at both the societal and individual level. Given ongoing population aging and general health decline in later life, alternative approaches to improve health among the middle to older-aged population are urgently needed (Olshansky et al., 2012). Therefore, coupled with a long-term investment in education, it is critical to empower populations who currently have, or who are at high risk of developing, health problems. One such approach is to encourage and promote continued learning over the life course, which has the potential to attenuate the cumulative negative effects of low-levels of formal educational attainment on health in middle to later adulthood (Narushima, 2008).

While there are a variety of organised adult education opportunities in the USA (e.g., Road Scholar, Osher Lifelong Learning Institute, etc) (Elderhostel Inc., 2014; The Bernard Osher Foundation, 2014), lifelong learning is broadly defined to include "all learning activity taken throughout life" (Commission of the European Communities, 2001: 9). Thus, in the present study, lifelong learning refers to any organised educational/learning activity reported after the completion of formal educational training. The compulsory education law in the USA requires those age 6 to 18 to attend school (12 years), and expected time of degree programme completion in higher education (e.g., college, university) is 2-4 years. While middle age and older adults are less likely than younger adults to participate in lifelong learning (OECD, 2014), approximately 50\% report participating in at least one lifelong learning activity per year (Cummins et al., 2015). Middle-age and older adults with lower levels of formal educational attainment, less income, and from racial/ethnic minorities, are less likely to participate in lifelong learning activities (Desjardins, 2010)

Given a positive association between formal educational attainment and subsequent lifelong learning participation (Desjardins, 2010), lifelong learning likely mediates the relationship between health and formal education through multifaceted pathways such as enhancing psychosocial resources, cognitive skills, social networks, and positive attitudes toward the future (Baker et al., 2011; Narushima et al., 2013; Schuller, 2004; Hammond and Feinstein, 2005). While lifelong learning appears to be a public health strategy worth pursuing, current evidence is limited in that empirical studies have generally employed relatively small samples, and national-level inquiry in the USA has yet to be conducted (Narushima, 2008; Schuller, 2004; Hammond, 2004). 
The relationship between health and lifelong learning in the USA has yet to be established (Chen et al., 2015; Hammond and Feinstein, 2006), and related research has predominantly focused on adult competencies (e.g., knowledge and skills) (Sørensen et al., 2012). Yet, lifelong learning may have great potential as a public health strategy (Green and Kreuter, 2005). By the same token, systematic mediation analysis with nationally representative US data is scant. Therefore, the current study addresses the following research question: does participation in lifelong learning activities mediate the relationship between self-rated health and formal educational attainment in middle to later adulthood? It is hypothesised that participation in lifelong learning activities attenuates the wellestablished link between self-rated health and formal educational attainment among adults aged 50-years and older.

\section{Methods}

\section{Data}

Data were obtained from the 2012 wave of the US Health and Retirement Study (HRS), which is a nationally representative panel study of the US residents aged 50-years and older. The HRS includes demographic, socioeconomic, and health characteristics. The detailed survey design and sampling procedure are published elsewhere (Hauser and Willis, 2004). A randomly selected subsample of HRS respondents-approximately half of the core module sample-was asked to complete a self-administered (i.e., a leave-behind) questionnaire focused on psychosocial and lifestyle issues. A lifelong learning measure was first added to this questionnaire in 2012 (Health and Retirement Study, 2014). Additional information was obtained from the RAND version of the HRS, which includes selected composite as well as derived variables (RAND Center for the Study of Aging, 2015). After excluding 212 cases with missing values ( $3 \%$ of the sample), the final sample size was 6,829. Except for the age and lifelong learning variables, all other variables had 1-32 cases with missing values. At the same time, more than $99.5 \%$ of the cases were available in all variables, and therefore, the listwise deletion of missing values was considered adequate.

\section{Measures}

\section{Dependent variable}

Self-rated health was recorded on a 5-point Likert-scale (1-5: Poor, Fair, Good, Very good, Excellent). Self-rated health is an informative indicator of current overall health, a powerful predictor of mortality among middle-aged to older adults, and a commonly examined health outcome in education-related research (Ferraro and Kelley-Moore, 2001).

\section{Independent variable}

Education was measured by total years of formal education obtained by the time of survey.

\section{Mediator}


Lifelong learning activity was based on responses to the question: "These first questions are about the activities in your life now. Please tell us how often you attend an educational or training course." Responses were recorded on a 7-point Likert-Scale (1-7: Never, Not in the last month, At least once a month, Several times a month, Once a week, Several times a week, Daily). Given a skewed distribution with a large proportion of "Never," this measure was dichotomised to compare those who currently participate in lifelong learning activities at least once a month versus those who do not.

\section{Covariates}

All covariates were selected according to their relevance for general health (U.S. Department of Health and Human Services, 2018), education, lifelong learning, and availability in the HRS. Demographic and socioeconomic characteristics include age (in years), gender (female vs. male), race/ethnicity [non-Hispanic white (reference); nonHispanic Black; Hispanic, and others], and marital status (married vs. not married). Household income and wealth (i.e., total non-housing assets) were converted into quintile ranks given skewed distributions and negative values (i.e., debt). Health-behaviour measures included frequency of vigorous, moderate, and light physical activity (1-5: Hardly ever or never, One to three times a month, Once a week, More than once a week, Everyday), smoking (current smoker vs. non-smoker), and heavy drinking (heavy drinker vs. non-heavy drinker: more than one drink and two drinks per day for women and men, respectively). Body mass index (BMI) was computed based on measures for height and weight.

\section{Statistical analysis}

Weighted descriptive statistics were computed using HRS-provided sampling weights (NLBWGTR, SECU, STRATUM). A mediation analysis is well-suited to address the research question, and we followed the structural equation model approach (i.e., path model) (Kline, 2016) depicted in Figure 1. Covariates (see Figure 1) were not shown in equations to aid with clearer presentation of key variables (i.e., formal educational attainment and current lifelong learning activity).

$$
\begin{gathered}
\text { Self-rated health } \left.=\beta_{0}+\beta_{1} \text { education }+\beta_{2} \text { lifelong learning activity }+\epsilon_{y} \text { (Equation } 1\right) \\
\text { Lifelong learning activity } \left.=\gamma_{10}+\gamma_{11} \text { education }+\epsilon_{m 1} \text { (Equation } 2\right)
\end{gathered}
$$

Let $\beta_{1}$ and $\beta_{2}$ be the regression coefficients for education and lifelong learning activity on self-rated health, respectively. $\gamma_{11}$ is the regression coefficient of education on lifelong learning activity. The mediation effect can be estimated as follows (Equation 3) (Muthén et al., 2016; Hayes, 2013)

Lifelong learning activity as the mediator: Indirect effect $=\beta_{2} \gamma_{11}$ (Equation 3)

Given that the product of two regression coefficients (i.e., $\beta_{2}$ and $\gamma_{11}$ ) violates the normality assumption, bootstrapping, which is the resampling technique currently 
recommended for mediation analyses (Hayes, 2013), was employed. Covariates were included in the models as shown in Figure 1.

Figure 1 about here

A mean and variance adjusted weighted least square with a probit link function was used for estimation, given the dichotomous mediator (Muthén et al., 2016). The MODEL CONSTRAINT function with 10,000 bootstrap samples in Mplus version 7 was used to estimate the adjusted indirect effect (Muthén and Muthén, 1998-2012; Stride et al., 2015; Mackinnon and Dwyer, 1993). Statistical significance was evaluated based on whether the bias-corrected bootstrap confidence interval included 0 or not. The estimated statistical power of the model was 0.95 , which is well above the 0.80 conventionally accepted level (Preacher and Coffman, 2006). In line with existing guidelines, model fit was assessed with a series of fit indices including the chi-square statistic, root mean square error of approximation (RMSEA), comparative fit index (CFI), and standardised root mean square residual (SRMR) (Kline, 2016). The final sampling weight (NLBWGTR), cluster weight (SECU) and stratification weight (STRATUM) was applied. For this type of study, formal consent is not required. The data analysed in this study was publicly available secondary data.

\section{Results}

Table 1 shows the demographic, socioeconomic, health, and health behaviour characteristics of the analytic sample. Approximately three-quarters of the respondents reported positive (good, very good, excellent) self-rated health. The average total-years of formal education was 13.17 years. In terms of lifelong learning activity, $17.16 \%$ of respondents reported participating at least once a month. Among the $82.84 \%$ of respondents that reported participating less than once a month, 70\% (57\% of the total sample) reported that they never participate in lifelong learning activities. Respondents were more likely to be female (54.20\%), white (78.59\%), and married (60.41\%). Less than half of the respondents engaged in vigorous physical activities, $80 \%$ engaged in moderate physical activity, and $90 \%$ engaged in light physical activity at least 1-3 times a month. Approximately $14 \%$ of the respondents were current smokers, and $7 \%$ were drinkers who consumed more alcohol more than recommended. Mean BMI was 28.62.

Table 1 about here

Table 2 shows the estimated 95\% bias-corrected bootstrap confidence intervals from the fully conditional mediation model. According to the recommended guidelines (Kline, 2016), the model achieved an adequate fit [chi-square statistic $=29.94$ (degrees of freedom $=6), p<0.05 ;$ RMSEA $=0.024<0.08 ; \mathrm{CFI}=0.959>0.90 ;$ SRMR $=0.010<0.10]$. Results supported our hypothesis that participation in lifelong learning activity attenuates the relationship between self-rated health and educational attainment after adjusting for relevant covariates. In view of the ratio of the estimated indirect effect and the total effect (effect size indicator) (MacKinnon et al., 2007), approximately 3.33\% to 5.45\% of the effect of formal education on self-rated health was mediated by participation in lifelong learning activities, which suggests that lifelong learning activity reflects a substantial pathway 
between self-rated health and formal educational attainment. Additionally, formal education was a significant predictor of both self-rated health and current participation in lifelong learning activities. That is, those with more years of formal education reported better self-rated health and they were also more likely to currently participate in at least one lifelong learning activity on a monthly basis.

Table 2 about here

\section{Discussion}

In the light of ongoing population aging and general health decline in later life, alternative approaches to improve health outcomes among middle-aged to older adults are urgently needed (Olshansky et al., 2012). From a theoretical viewpoint, lifelong learning is an attractive public health strategy. Findings from the present study suggest that lifelong learning likely mediates the pervasive and cumulative effects of educational attainment on health in later life. To our knowledge, these findings reflect the first nationally representative evidence of the association between health and lifelong learning in the USA.

These initial findings are promising, but given a lack of longitudinal panel data, we are severely limited in our ability to address causal mechanisms. The HRS is conducted biannually, and a second wave of data (i.e., the 2014 Leave-Behind Questionnaire) has recently been released. Yet, true longitudinal mediation analysis requires at least three waves of panel data to properly identify effects (Collins et al., 1998). Thus, in the absence of such data at this time, we offer three potential explanations for how participation in lifelong learning activity likely mediates the relationship between health and formal educational attainment, with the intent to guide future research.

First, lifelong learning activity is positively associated with adult competencies (e.g., knowledge and skills, such as those necessary for self-care skills) (Sørensen et al., 2012), which reflects a similar, but distinct, pathway that has been established between health and formal educational attainment (Hayward et al., 2015). Continuing education through lifelong learning likely enhances cognitive skills (e.g., problem-solving skills), which potentially provides health advantages (Baker et al., 2011). Thus, it may be useful for research focused on specific competencies and cognition factors to identify precise pathways by which lifelong learning may improve health through improving one's health-related knowledge base, either directly or indirectly (e.g., health-related versus general lifelong learning activity). Moreover, future research that identifies age patterns in the link between cognition, lifelong learning, and one's ability to translate new knowledge into improved health behaviours would be useful for developing refined targeting strategies.

Second, participation in lifelong learning activity is associated with psychological benefits and may enhance one's self-esteem, sense of control, and positive attitudes toward life, which in turn are associated with positive health outcomes (Schuller, 2004). Moreover, positive experiences with lifelong learning stimulates motivation for subsequent participation (Pressman et al., 2009), and ongoing active engagement in social and productive activities is a major component of the successful aging paradigm (Rowe and Kahn, 1997). However, there is a lack of generalisable evidence to support these proposed psychological benefits. Thus, future research that draws on nationally representative data, such as the HRS, is needed to establish these links. This may be a fruitful area of research for scholars who work within the successful aging paradigm, as this theoretical framework 
provides a foundation for linking health outcomes with psychosocial factors in later life (e.g., activie social engagement).

Third, previous research concerned with addressing fundamental links between health and socioeconomic status has highlighted the importance of considering differential levels of experienced and perceived stress (Braveman et al., 2011). Thus, links between enhanced coping behaviours, which are associated with related psychological benefits (enhanced self-esteem, sense of control, and positive attitudes toward life), and lifelong learning must be explored. Indeed, specific pathways between health and lifelong learning activity require further research. Particularly, the type (i.e., formal vs. informal) and amount (e.g., dose-response) of lifelong learning activity required to impact health warrants critical attention. In addition, practical plans for recruitment and retention of mature adults in a variety of lifelong learning activities should be identified (Chang and Lin, 2011; Yamashita et al., 2015). In sum, present findings point to the potential of lifelong learning as an important public health strategy in middle to later life, and there is strong theoretical support to further explore the roles that competency, psychosocial resources, and coping play in the links between health and lifelong learning activity.

\section{Limitations}

First, possible omitted variable bias such as previous lifelong learning experience, personality, and place of residence cannot be ruled out (Clouston et al., 2015). Second, relevant theoretical propositions were used to guide our analytic approach, but the crosssectional data employed in this analysis does not allow for explicit causal inference. This limitation can be largely overcome in time, with the accumulation of longitudinal panel data. Specially, the lifelong learning measure will soon be available in three waves of the HRS, and future research should consider building on the baseline findings reported in this study. Yet, the operationalisation of lifelong learning activity is limited to the frequency of participation in a generic category of "adult education and training." Thus, the type, quality, and intensity of learning activity remains unclear. However, given the lack of previous generalisable evidence in the US context, a general measure of lifelong learning participation was appropriate for this study. More detailed measures of lifelong learning activity should be included in future waves of inter/nationally representative surveys, such as the HRS and the Program for International Assessment of Adult Competencies (PIAAC) (National Center for Education Statistics, 2017). Finally, findings from this study should not be extended to other nations.

\section{Contribution}

Our use of a systematic mediation analytic technique (i.e., structural equation model with bootstrapping) is rare in the related body of previous research, and this study bolsters findings from previous studies that employed different methodological techniques (Narushima et al., 2013; Jenkins, 2011; Leung and Liu, 2011). Finally, we provided empirical evidence based on an informed approach, which could have policy implications in multiple domains (e.g., aging, education and public health).

\section{Public health implications}


The identification of mediators of the fundamental causes of health is an indispensable first step toward improving population health (Hatzenbuehler et al., 2013). Activity aspects (i.e., participation) of lifelong learning have received insufficient attention compared to adult competencies (e.g., capability, skills, knowledge), and current findings suggest that participation in lifelong learning activity may be a public health strategy worth pursuing. Similar to the fact that both physical fitness and physical activity benefit health outcomes, lifelong learning activity should be considered among the commonly recognised health promoting factors.

Lifelong learning activity could provide an additional opportunity for individuals who are already engaged in healthful behaviours (e.g., physical activity), as well as for individuals who dislike, and/or have limited access to environments, conducive for physical activity. Considering only one-in-five adults engaged in physical activity at the recommended level, lifelong learning as an additional healthful activity has the potential to reach a relatively large proportion of those who would otherwise be left out (Centers for Disease Control and Prevention, 2014). Lifelong learning can be autonomously done by middle-aged to older adults, and is considered a sustainable opportunity that enhances individual empowerment, which is positively associated with self-directed health management (Sørensen et al., 2012). Empowerment through lifelong learning is also relevant for specific health care issues surrounding the need to quickly learn and adopt self-care regimens and master new healthrelated information (Krumholz 2013) (e.g., post-hospital syndrome --- greater risk of rehospitalisation within 30 days of discharge among one in five or over 2.6 million Medicare patients).

Moving forward, it is important to consider the availability of, and infrastructure for, lifelong learning programmes and how this may limit accessibility. Existing studies (largely from European nations) confirm the importance of policies aimed at maximising lifelong learning participation at the population level (above and beyond a focus on individual choices) (Roosmaa and Saar, 2017; White, 2012). For example, such policies have addressed situational (e.g., family responsibility, child care) and institutional barriers (e.g., cost, transportation, prerequisite) to lifelong learning (Broek and Hake, 2012; Roosmaa and Saar, 2017). There are also barriers among non-employed adults, presumably due to a strong emphasis placed on the links between lifelong learning and economic returns (Boeren et al., 2010). However, universally effective policies have yet to be documented (Desjardins, 2010). Given emerging generalisable empirical evidence of the health benefits associated with lifelong learning, more resources should be allocated to increase lifelong learning opportunities as a health promotion strategy for middle-age and older populations.

In conclusion, findings from the current study based on the analysis of nationally representative data (i.e., the 2012 wave of the Health and Retirement Study) showed that lifelong learning mediates approximately $3 \%$ to $5 \%$ of the well-established link between health and formal educational attainment among middle-aged and older adults in the USA. Although educational attainment is a powerful determinant of health in later life, participation in lifelong learning activity has great potential to attenuate this relationship. Indeed, as a health promotion strategy, lifelong learning can be autonomously and sustainably carried out at any stage of the life course. Public health, education, and aging policies should encourage lifelong learning activity and promote accessibility to relevant programmes.

The present study provided empirical evidence based on an informed approach that should act as a basis for future research, which may also be useful for preliminary policy 
directives aimed at activity-based public health promotion. Although more research is needed to confirm findings from this study and to identify detailed pathways, public health, aging, and education policy plays a critical role in resource allocation for improving accessibility to lifelong learning programmes and related community-based activities.

\section{Acknowledgement}

The authors report no conflict of interest in this study. 


\section{References}

Baker DP, Leon J, Smith Greenaway EG, et al. (2011) The Education Effect on Population Health: A Reassessment. Population and Development Review 37: 307-332.

Boeren E, Nicaise I and Baert H. (2010) Theoretical models of participation in adult education: The need for an integrated model. International journal of lifelong education 29: 45-61.

Braveman PA, Egerter S and Williams DR. (2011) The social determinants of health: coming of age. Annual review of public health 32: 381-398.

Broek S and Hake BJ. (2012) Increasing participation of adults in higher education: Factors for successful policies. International Journal of Lifelong Education 31: 397-417.

Centers for Disease Control and Prevention. (2014) Facts about physical activity Available at: https://www.cdc.gov/physicalactivity/data/facts.htm.

Chang D-F and Lin S-P. (2011) Motivation to learn among older adults in Taiwan. Educational Gerontology 37: 574-592.

Chen M, Lee C, Staley M, et al. (2015) The association of lifelong learning and cognitive function: Findings from the health and retirement study. The Gerontologist 55: 480480.

Clouston SAP, Richards M, Cadar D, et al. (2015) Educational Inequalities in Health Behaviors at Midlife. Journal of Health and Social Behavior 56: 323-340.

Collins LM, Graham JJ and Flaherty BP. (1998) An alternative framework for defining mediation. Multivariate Behavioral Research 33: 295-312.

Commission of the European Communities. (2001) Making a European area of lifelong learning a reality. Brussels, Belgium.

Cummins PA, Kunkel SR and Walkter RM. (2015) Adult education and training programs for older adults in the U.S. National results adn cross-national comparisons using PIAAC data.

Cutler DM and Lleras-Muney A. (2010) Understanding differences in health behaviors by education. Journal of Health Economics 29: 1-28.

Desjardins R. (2010) Participation in adult learning. In: Peterson P, Baker E and McGaw B (eds) International Encyclopedia of Education. New York: Elsevier Science, 240-250.

Dupre ME. (2007) Educational Differences in Age-Related Patterns of Disease: Reconsidering the Cumulative Disadvantage and Age-As-Leveler Hypotheses. Journal of Health and Social Behavior 48: 1-15.

Elderhostel Inc. (2014) The history of Elderhostel and Road Scholar. Available at: http://www.roadscholar.org/about/history.asp.

Ferraro KF and Kelley-Moore JA. (2001) Self-Rated Health and Mortality Among Black and White AdultsExamining the Dynamic Evaluation Thesis. The Journals of Gerontology: Series B 56: S195-S205.

Green LW and Kreuter MW. (2005) Health promotion planning: an educational and ecological approach, Boston: McGraw-Hill

Hammond C. (2004) Impacts of lifelong learning upon emotional resilience, psychological and mental health: fieldwork evidence. Oxford Review of Education 30: 551-568.

Hammond C and Feinstein L. (2005) The effects of adult learning on self-efficacy. London Review of Education 3: 265-287. 
Hammond C and Feinstein L. (2006) Are those who flourished at school healthier adults? What role for adult education?[Wider Benefits of Learning Research Report No. 17], London, United Kingdom: Centre for Research on the Wider Benefits of Learning.

Hatzenbuehler ML, Phelan JC and Link BG. (2013) Stigma as a Fundamental Cause of Population Health Inequalities. American Journal of Public Health 103: 813-821.

Hauser RM and Willis RJ. (2004) Survey Design and Methodology in the Health and Retirement Study and the Wisconsin Longitudinal Study. Population and Development Review 30: 209-235.

Hayes AF. (2013) Introduction to mediation, moderation, and conditional process analysis: A regression-based apporach, New York: The Guilford Press.

Hayward MD, Hummer RA and Sasson I. (2015) Trends and group differences in the association between educational attainment and U.S. adult mortality: Implications for understanding education's causal influence. Social Science \& Medicine 127: 8-18.

Health and Retirement Study. (2014) 2012 Core: Data description and usage. Available at: http://hrsonline.isr.umich.edu/modules/meta/2012/core/desc/h12dd.pdf.

Jenkins A. (2011) Participation in learning and wellbeing among older adults. International Journal of Lifelong Education 30: 403-420.

Kline RB. (2016) Principals and practice of structural equation modeling, New York: The Guilford Press.

Krumholz HM. (2013) Post-Hospital Syndrome - An Acquired, Transient Condition of Generalized Risk. New England Journal of Medicine 368: 100-102.

Leung DSY and Liu BCP. (2011) Lifelong Education, Quality of Life and Self-Efficacy of Chinese Older Adults. Educational Gerontology 37: 967-981.

Mackinnon DP and Dwyer JH. (1993) Estimating Mediated Effects in Prevention Studies. Evaluation Review 17: 144-158.

MacKinnon DP, Fairchild AJ and Fritz MS. (2007) Mediation Analysis. Annual Review of Psychology 58: 593-614.

Mirowsky J and Ross CE. (2015) Education, Health, and the Default American Lifestyle. Journal of Health and Social Behavior 56: 297-306.

Muthén BO and Muthén LK. (1998-2012) Mplus statistical analysis with latent variables: User's guide, Los Angeles: Muthén \& Muthén.

Muthén BO, Muthén LK and Asparouhov T. (2016) Regression and mediation analysis using Mplus, Los Angeles: Muthén \& Muthén.

Narushima M. (2008) More than nickels and dimes: the health benefits of a community based lifelong learning programme for older adults. International Journal of lifelong education 27: 673-692.

Narushima M, Liu J and Diestelkamp N. (2013) The Association Between Lifelong Learning and Psychological Well-Being Among Older Adults: Implications for Interdisciplinary Health Promotion in an Aging Society. Activities, Adaptation \& Aging 37: 239-250.

National Center for Education Statistics. (2017) Program for the International Assessment of Adult Competencies (PIAAC) 2012/2014: U.S. National Supplement Restricted Use Data Files-Household. Available at: https://nces.ed.gov/pubsearch/pubsinfo.asp?pubid=2016668rev.

OECD. (2014) Education at a glance 2014. OECD Indicators.

Olshansky SJ, Antonucci T, Berkman L, et al. (2012) Differences In Life Expectancy Due To Race And Educational Differences Are Widening, And Many May Not Catch Up. Health Affairs 31: 1803-1813. 
Phelan JC, Link BG and Tehranifar P. (2010) Social Conditions as Fundamental Causes of Health Inequalities: Theory, Evidence, and Policy Implications. Journal of Health and Social Behavior 51: S28-S40.

Preacher KJ and Coffman DL. (2006) Computing power and minimum sample size for RMSEA.

Pressman SD, Matthews KA, Cohen S, et al. (2009) Association of Enjoyable Leisure Activities With Psychological and Physical Well-Being. Psychosomatic medicine 71: 725-732.

RAND Center for the Study of Aging. (2015) RAND HRS Data Documentation, Version O. In: Aging RCftSo (ed). Santa Monica, CA.

Roosmaa E-L and Saar E. (2017) Adults who do not want to participate in learning: a crossnational European analysis of their perceived barriers. International Journal of Lifelong Education 36: 254-277.

Rowe JW and Kahn RL. (1997) Successful aging. The Gerontologist 37: 433-440.

Schuller T. (2004) Three capitals: A framework. In: Schuller T, Preston J, Hammond C, et al. (eds) The benefit of learning: The impact of education on health, family life and social capital. London, United Kingdom: RoutledgeFalmer, 12-33.

Sørensen K, Van den Broucke S, Fullam J, et al. (2012) Health literacy and public health: A systematic review and integration of definitions and models. BMC Public Health 12: 80.

Stride CB, Gardner S, Catley N, et al. (2015) Mplus code for the mediation, moderation, and moderated mediation model templates from Andrew Hayes' PROCESS analysis examples. Available at:

http://www.offbeat.group.shef.ac.uk/FlO/mplusmedmod.htm.

The Bernard Osher Foundation. (2014) Osher Lifelong Learning Institutes. Available at: http://www.osherfoundation.org/index.php?olli.

U.S. Department of Health and Human Services. (2018) Healthy People 2020: Determinants of health. Available at: https://www.healthypeople.gov/2020/about/foundationhealth-measures/Determinants-of-Health.

White P. (2012) Modelling the 'learning divide': predicting participation in adult learning and future learning intentions 2002 to 2010. British Educational Research Journal 38: 153-175.

Yamashita T, López EB, Keene JR, et al. (2015) Predictors of Adult Education Program Satisfaction in Urban Community-Dwelling Older Adults. Educational Gerontology 41: 825-838. 
Table 1: Weighted Descriptive Summary of the Respondents

Variable

Weighted mean (SE) or percentage (SE)

Self-rated health
Excellent
Very good
Good
Fair
Poor

$11.58 \%(0.58)$

$32.34 \%(0.78)$

$30.68 \%(0.74)$

$18.36 \%(0.51)$

$7.04 \%(0.41)$

Years of education

$13.17(0.07)$

Lifelong learning activity

At least once a month

$17.16 \%(0.50)$

Less than once a month \& Never

$82.84(0.85)$

Age (years)

$65.86(0.27)$

Gender (women)

$54.20 \%(0.56)$

Race and ethnicity

Non-Hispanic White (reference)

$78.59 \%(1.03)$

Non-Hispanic Black

$9.84 \%(0.69)$

$8.18 \%(0.85)$

Hispanic

$3.26 \%(0.36)$

Marital status (married)

$60.41 \%(0.92)$

Household income

$$
\begin{aligned}
& 1^{\text {st }} \text { quintile } \\
& 2^{\text {nd }} \\
& 3^{\text {rd }} \\
& 4^{\text {th }} \\
& 5^{\text {th }}
\end{aligned}
$$

$18.03 \%(0.65)$

$17.00 \%(0.61)$

$17.86 \%(0.78)$

$21.57 \%(0.83)$

$25.54 \%(1.06)$

Household wealth (total non-housing assets)

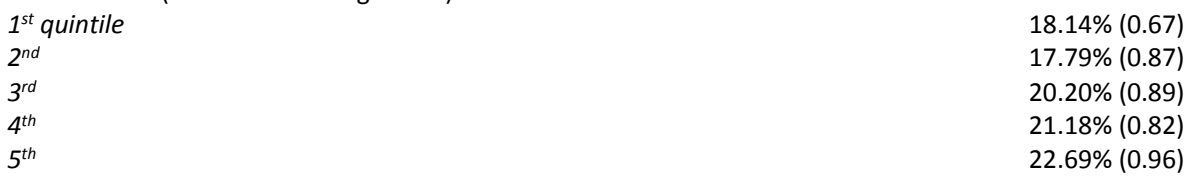

$18.14 \%(0.67)$

$2^{\text {nd }}$

$3^{\text {rd }}$

$17.79 \%(0.87)$

$20.20 \%(0.89)$

$21.18 \%(0.82)$

$5^{\text {th }}$

$22.69 \%(0.96)$

Vigorous physical activity

Everyday

$2.21 \%(0.26)$

More than once a week

$25.02 \%(0.81)$

Once a week

$11.73 \%(0.63)$

One to three times a month

$9.36 \%(0.50)$

Hardly ever or never

$51.68 \%(1.01)$

Moderate physical activity

Everyday

$7.60 \%(0.50)$

More than once a week

$44.40 \%(1.13)$

Once a week

$16.76 \%(0.53)$

One to three times a month

$11.49 \%(0.50)$

Hardly ever or never

$19.75 \%(0.65)$

Light physical activity

$$
\text { Everyday }
$$

$9.47 \%(0.53)$

More than once a week

$48.84 \%(1.01)$

Once a week

$24.15 \%(0.84)$

One to three times a month

$7.26 \%(0.45)$

Hardly ever or never

$10.28 \%(0.48)$

Smoking (current smoker)

$14.01 \%(0.65)$

Heavy drinking (heavy drinker)

$7.11 \%(0.49)$

Body mass index

$28.62(0.11)$

Note: $\mathrm{SE}=$ Standard error

The weighted descriptive summary was estimated based on 7,248 respondents in the Health and Retirement Study 2012 wave

The final survey weights (NLBWGTR), cluster weight (SECU) and stratification weight (STRATUM) were applied in the estimation 
Table 2: 95\% Bias-Corrected Bootstrap Confidence Intervals of the Estimated Coefficients from the Fully Conditional Mediation Model

\begin{tabular}{|c|c|c|c|}
\hline Dependent variable & Independent or mediator variable & Lower limit & Upper limit \\
\hline Self-rated health & Years of education * & 0.029 & 0.053 \\
\hline \multirow[t]{15}{*}{ (5-point Likert-Scale) } & Lifelong learning activity (at least once a month) * & 0.029 & 0.122 \\
\hline & Age (years) & -0.006 & 0.001 \\
\hline & Gender (women) * & 0.093 & 0.191 \\
\hline & Non-Hispanic Black (vs. Non-Hispanic White) & -0.075 & 0.066 \\
\hline & Hispanic (vs. Non-Hispanic White) & -0.200 & 0.061 \\
\hline & Others (vs. Non-Hispanic White) & -0.213 & 0.100 \\
\hline & Marital status (married vs. not married) & -0.031 & 0.090 \\
\hline & Household income (Quintile rank) * & 0.059 & 0.128 \\
\hline & Household wealth (Quintile rank) * & 0.070 & 0.120 \\
\hline & Vigorous physical activity (5-point Likert-Scale) * & 0.097 & 0.141 \\
\hline & Moderate physical activity (5-point Likert-Scale) * & 0.093 & 0.136 \\
\hline & Light physical activity (5-point Likert-Scale) ${ }^{*}$ & 0.063 & 0.127 \\
\hline & Smoking (current smoker vs. non-smoker) ${ }^{*}$ & -0.345 & -0.140 \\
\hline & Heavy drinking (heavy drinker vs. non-heavy drinker) & -0.122 & 0.077 \\
\hline & Body mass index * & -0.022 & -0.013 \\
\hline Lifelong learning activity & Years of education * & 0.053 & 0.109 \\
\hline \multirow[t]{8}{*}{ (7-point Likert-Scale) } & Age (years) * & -0.021 & -0.010 \\
\hline & Gender (women) * & 0.091 & 0.276 \\
\hline & Non-Hispanic Black (vs. Non-Hispanic White) * & 0.090 & 0.357 \\
\hline & Hispanic (vs. Non-Hispanic White) ${ }^{*}$ & -0.040 & 0.381 \\
\hline & Others (vs. Non-Hispanic White) & -0.335 & 0.332 \\
\hline & Marital status (married vs. not married) ${ }^{*}$ & -0.268 & -0.065 \\
\hline & Household income (Quintile rank) * & 0.084 & 0.179 \\
\hline & Household wealth (Quintile rank) * & -0.034 & 0.062 \\
\hline Mediation effect & Lifelong learning * & 0.001 & 0.003 \\
\hline
\end{tabular}

Model fit indices

$\begin{array}{rc}\text { Chi-square statistic (DF) } & 29.938(6), p<0.05 \\ \text { RMSEA } & 0.024 \\ \text { CFI } & 0.959 \\ \text { SRMR } & 0.010\end{array}$

Note: $\left({ }^{*}\right)$ The estimated effect was considered statistically significant when the $95 \%$ bias-corrected bootstrap confidence intervals did not include 0 .

The model adjusted for all regression and correlation paths shown in Figure 1.

The final survey weight (NLBWGTR) was applied for this model.

The final sample size $=6,829$

$\mathrm{DF}=$ degrees of freedom; RMSEA = root mean square error of approximation; CFI = comparative fit index; SRMR = Standardised root mean square residual 
Figure 1: Fully Conditional Mediation Model for Education, Lifelong Learning Activity and Self-rated Health

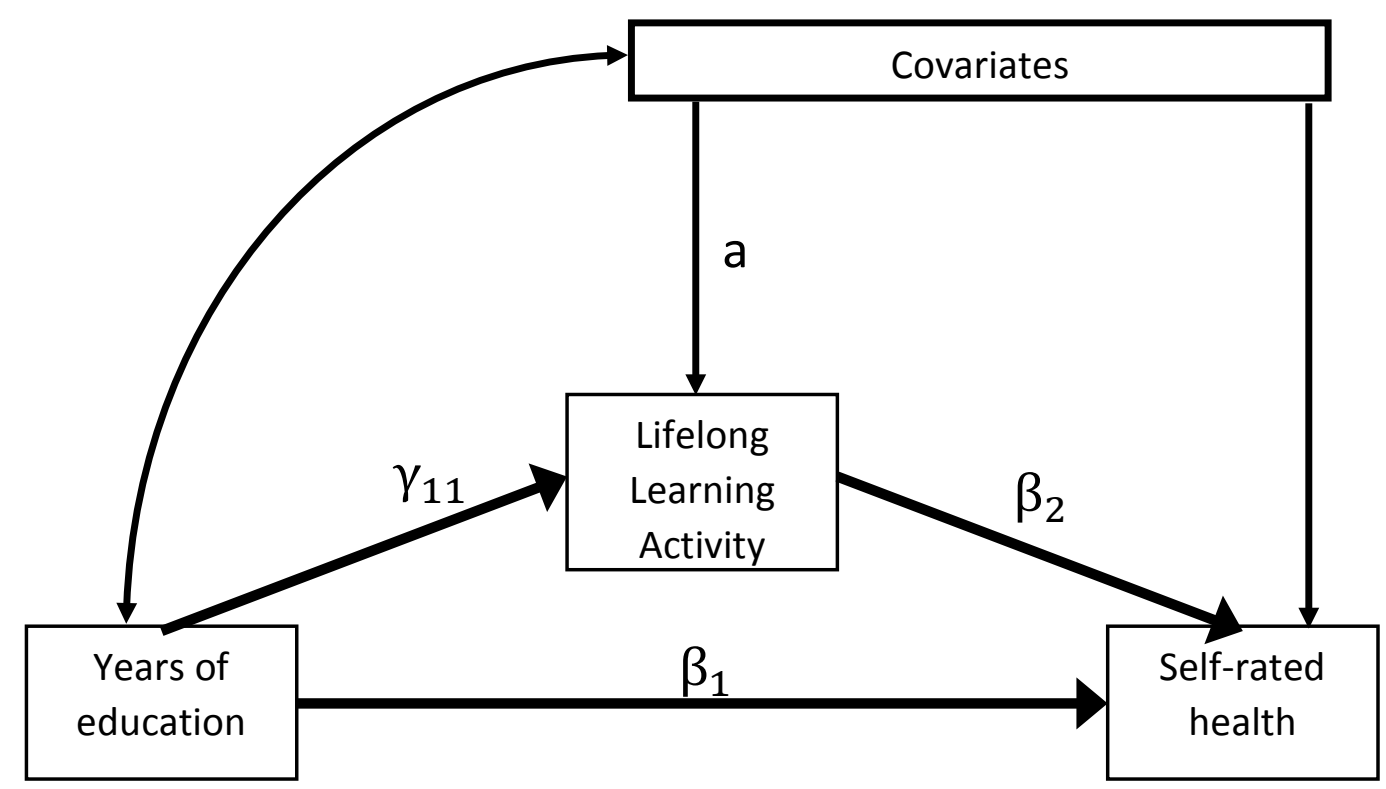

Note: Straight line represents the regression path; curved line represents the correlation between variables.

a. Only the demographic and socioeconomic characteristics were specified for the regression paths from the covariates to lifelong learning activity (see Table 3 for the list of variables). 